\title{
Influência da sílica ativa e do metacaulim na velocidade de carbonatação do concreto: relação com resistência, absorção e relação a/c
}

\author{
Influence of silica fume and metakaolin on carbonation \\ rate of concrete: relationship with strength, absorption \\ and $\mathrm{w} / \mathrm{c}$ ratio
}$$
\begin{aligned}
& \text { Marcelo Henrique Farias de Medeiros } \\
& \text { Janderson William Raisdorfer } \\
& \text { Juarez Hoppe Filho }
\end{aligned}
$$

Resumo

sílica ativa e o metacaulim são adições de elevada reatividade que $\triangle$ podem ser usadas como substituição parcial do cimento ou como 1 simples adição, aumentando a quantidade de aglomerante no compósito. Por outro lado, o processo de carbonatação é importante para a vida útil de estruturas de concreto armado devido a sua influência na corrosão. Este trabalho objetiva estudar a influência do uso da sílica ativa e do metacaulim, empregados como adição e substituição parcial do cimento, na velocidade de carbonatação do concreto. Além disso, foi investigada a relação da carbonatação com a absorção, relação água/cimento e resistência à compressão do concreto. Desse modo, foi fixado um traço de concreto de 1,0:2,25:3,00 com água/aglomerante de 0,5 e empregou-se $10 \%$ de adição e substituição de cimento. No caso do uso como adição, o traço unitário ficou modificado para 1,0:2,05:2,73 com água/aglomerante de 0,5 , como uma consequência inerente da adição. Os resultados indicam que a resistência à compressão, a absorção e a relação água/cimento apresentam influência na velocidade de carbonatação e, quando relacionadas ao coeficiente de carbonatação por meio de um índice que considere a influência conjunta destas grandezas, apresentam elevada representatividade. Um exemplo disso é o coeficiente proposto designado $K_{(\text {sorvidade.a/c)ffc }}$.

Palavras-chave: Sílica ativa. Metacaulim. Carbonatação. Reserva alcalina. Concreto. Durabilidade.

Marcelo Henrique Farias de Medeiros Universidade Federal do Paraná Curitiba - PR - Brasil

Janderson William Raisdorfer Universidade Federal do Paraná Curitiba - PR - Brasil

Juarez Hoppe Filho Universidade Federal do Oeste da - Bahia Barreiras - BA - Brasil

Recebido em 02/05/16 Aceito em 20/04/17

Abstract

Silica fume and metakaolin are high reactivity additions that can be used with partial cement replacement or the simple addition principle, increasing the amount of binder in the composite. On the other hand, the carbonation process is important for the service life of reinforced concrete structures due to its influence on steel reinforcement corrosion. This research aims to investigate the influence of silica fume and metakaolin used as addition or partial cement replacement on concrete carbonation. Furthermore, the relationship of carbonation with absorption, water/cement ratio and compressive strength of the concrete was investigated. Thus, a 1.0: 2.25: 3.00 concrete mixture with 0.5 water/binder was fixed and 10\% cement addition and replacement was used. In the case of the use as addition, the unit mixture was changed to 1.0: 2.05: 2.73 with water/ binder 0.5, as an inherent consequence of the addition. The results indicate that the compressive strength, the absorption and the water/cement ratio influence the carbonation rate and, when related to the carbonation coefficient using an index considering the joint influence of these quantities, are highly representative. An example of this is the proposed coefficient designated as K(sorptivity.water/cement)/compressive strength.

Keywords: Silica fume. Metakaolin. Carbonation. Alkalinity. Concrete. Durability.
\end{abstract}

MEDEIROS, M. H. F. de; RAISDORFER, J. W.; HOPPE FILHO, J. Influência da sílica ativa e do metacaulim na velocidade 125 de carbonatação do concreto: relação com resistência, absorção e relação a/c. Ambiente Construído, Porto Alegre, v. 17, n. 4, p. 125-139, out./dez. 2017. 


\section{Introdução}

As adições minerais pozolânicas podem ser incorporadas ao cimento Portland durante o processo de fabricação do material ou utilizado como adição in loco para a execução de concretos e argamassas. A incorporação de adições minerais à composição do cimento propicia vantagens econômicas e ambientais, além de interferir na microestrutura da matriz hidratada, incrementando, na maioria das vezes, a durabilidade das obras executadas com esse material ligante (HOPPE FILHO et al., 2013, 2017).

Além de aspectos referentes aos tipos de pozolanas e fatores relativos à produção e ao teor de adições minerais, os efeitos da atividade pozolânica na durabilidade do concreto em meios agressivos são abordados em diversos trabalhos, tais como Medeiros et al. (2012), os quais desenvolveram um estudo focado em ambiente marinho; Heede e Belie (2014) e Marques, Chastre e Nunes (2013), focados no estudo sobre a resistência à carbonatação; Lee $e t$ al. (2011) e Zerbino et al. (2012), que estudaram o efeito das pozolanas na capacidade de mitigação da reação álcali-agregado (RAA); Hodhod e Salama (2013) e Hoppe Filho et al. (2015), que focaram seus estudos na durabilidade com relação ao ataque por sulfatos; e Pacheco-Torgal e Jalali (2009), que pesquisaram o efeito das pozolanas na durabilidade em ambientes ácidos.

As adições minerais podem ser usadas com diferentes funções, de forma a modificar várias propriedades do concreto, podendo ou não ser positivas a depender do tipo de aplicação. De acordo com Possan (2010) e Papadakis (2000), concretos com relações água/aglomerante menores do que 0,45 podem ser considerados com velocidade de carbonatação praticamente desprezível, mas acima desse limite o aumento na relação água/aglomerante e o aumento no teor de pozolana podem acelerar o processo de carbonatação.

A redução do teor de portlandita no compósito de cimento Portland pode facilitar o processo de carbonatação, contudo, o refinamento dos poros devido a atividade pozolânica e o aumento no empacotamento de partículas tende a criar uma barreira física ao ingresso de $\mathrm{CO}_{2}$, o que reduz o efeito da carbonatação. Desse modo, a carbonatação não é exclusivamente relacionada com a alcalinidade do concreto, como será evidenciado no experimento deste trabalho.

Ao considerar que a carbonatação pode ser afetada pela introdução das adições pozolânicas na composição do concreto e que o emprego dessas adições pode ser realizado por simples adição ou por substituição parcial do cimento Portland, este programa experimental foi delineado com o objetivo de entender o efeito do emprego de metacaulim e sílica ativa na velocidade de carbonatação e sua relação com a resistência à compressão, a absorção, a reserva alcalina e a relação a/c do concreto.

\section{Programa experimental}

Neste trabalho, os concretos foram dosados seguindo dois raciocínios: 1 - dosagem da adição em substituição parcial de $10 \%$, em massa, ao consumo de cimento Portland; 2 - dosagem da adição mineral em acréscimo de 10\%, em massa, ao consumo de cimento. O motivo de usar esses dois meios de introdução das adições minerais é que são realmente duas formas possíveis de usar as adições minerais em uma dosagem de concreto. É importante destacar que o caso da substituição é mais indicado por manter o proporcionamento dos aglomerantes em massa, ou seja, mantém o traço do concreto em massa. No caso do uso em adição, a quantidade global de aglomerante é aumentada e, como a representação de um traço se refere ao aglomerante, o traço efetivo acaba sendo modificado. Isso pode ser constatado na Tabela 1 , por meio da comparação do traço unitário da série de referência com o das séries com o uso de metacaulim e sílica ativa como adição. Papadakis (2000) também apresentou um estudo seguindo esse mesmo raciocínio de emprego de pozolanas como substituição ou adição ao cimento, sendo uma das principais referências para este trabalho experimental.

As variáveis independentes deste trabalho são:

(a) tipo de adição pozolânica (2 níveis metacaulim e sílica ativa);

(b) tipo de estratégia de emprego na mistura (2 níveis - adição e substituição parcial ao cimento Portland).

Além disso, as variáveis dependentes ou de resposta principais são:
(a) resistência à compressão;
(b) sorvidade;
(c) velocidade de carbonatação acelerada.

Deve-se destacar que, em todos os casos de medição das variáveis de resposta, os ensaios foram realizados em cinco corpos de prova irmãos.

O teor de 10\%, em massa, foi escolhido por ser um valor médio do emprego das adições pozolânicas de alta reatividade. Por se tratar de um estudo sobre o 
efeito de adições pozolânicas, optou-se por usar o cimento Portland mais puro comercializado do mercado brasileiro, o CP V - ARI.

A Tabela 1 mostra um resumo dos concretos utilizados representados em massa. Note-se que a relação água/aglomerante foi mantida constante e o concreto teve sua fluidez fixada de modo a apresentarem slump de $10 \pm 2 \mathrm{~cm}$. Para regular a fluidez foi utilizado um aditivo superplastificante à base de policarboxilato em meio aquoso, com densidade de $1,07 \mathrm{~g} / \mathrm{cm}^{3}$ e $\mathrm{pH}$ de $4,5 \pm 1,0$. A resistência à compressão foi um parâmetro de controle deste estudo e foi determinada a partir da compressão de corpos de prova cilíndricos de $\emptyset 10$ x $20 \mathrm{~cm}$, aos 28 dias, seguindo a NBR 5739 (ABNT, 2007).

Todos os concretos deste trabalho foram curados de acordo com a NBR 5738 (ABNT, 2015) em câmara úmida com ambiente controlado em $95 \pm 5 \%$ de umidade relativa e temperatura de $23 \pm 2{ }^{\circ} \mathrm{C}$ até os 28 dias.

\section{Ensaio de carbonatação acelerada}

Após o tempo de cura úmida de 28 dias, os corpos de prova passaram por um período de condicionamento em câmara seca $(55 \pm 5 \%$ de umidade relativa e $23 \pm 3{ }^{\circ} \mathrm{C}$ ) até constância de massa. O período de condicionamento durou 20 dias para todos os corpos de prova deste experimento e teve o objetivo de secar o concreto de modo a permitir o ingresso do dióxido de carbono. As condições internas da câmara de carbonatação acelerada foram controladas de modo a ter $5 \pm 1 \%$ de $\mathrm{CO}_{2}$ e $60 \pm 0,5 \%$ de umidade relativa. Os corpos de provas empregados foram cilíndricos de $\varnothing 10 \times 20 \mathrm{~cm}$ e as leituras foram realizadas a partir da face externa no sentido do centro da circunferência, como ilustra a Figura 1. Para cada corpo de prova, recém-fraturado, foram realizadas seis leituras, uma a cada $60^{\circ}$. O procedimento seguiu recomendações do documento CPC-18 (RILEM, 1988).

Para a obtenção dos coeficientes de carbonatação, foram mensuradas leituras de profundidade de carbonatação nas idades de $1,4,8$ e 12 semanas. Essas leituras foram ajustadas ao modelo de Tuutti (1982), apresentado na Equação 1, onde $\boldsymbol{e}_{\boldsymbol{c}}$ é a espessura carbonatada $(\mathrm{mm}), \mathrm{K}_{\mathrm{CO}_{2}}$ é o coeficiente de carbonatação a ser calculado $\left(\mathrm{mm} / \mathrm{semana}^{0,5}\right)$ e $\boldsymbol{t}$ é o tempo, em semanas.

$e_{c}=K_{\mathrm{CO}_{2}} \cdot \sqrt{t}$

Eq. 1

Como os resultados das leituras de carbonatação se comportam como uma equação exponencial, para determinar o valor de $K_{\mathrm{CO}_{2}}$, o gráfico de profundidade de carbonatação versus tempo foi linearizado a partir da representação da raiz quadrada do tempo no eixo $\mathrm{X}$, como apresentado na Figura 2. Desse modo, o coeficiente angular da reta que relaciona a profundidade de carbonatação em função da raiz do tempo representa o coeficiente de carbonatação.

Tabela 1 - Proporcionamento de materiais dos concretos representados em massa

\begin{tabular}{|c|c|c|c|c|c|c|c|}
\hline \multicolumn{8}{|c|}{ Traço unitário teórico (Referência) } \\
\hline Aglomerante & Areia & Brita & & a/agl. & \multicolumn{3}{|c|}{ Consumo de cimento $\left(\mathrm{Kg} / \mathrm{m}^{3}\right)$} \\
\hline 1,00 & 2,25 & 3,00 & & 0,5 & & 353 & \\
\hline \multicolumn{8}{|c|}{ Traço em massa (Referência) } \\
\hline a/agl. & Volume $\left(\mathrm{m}^{3}\right)$ & \multicolumn{2}{|c|}{ Cimento $(\mathrm{Kg})$} & \multirow{2}{*}{$\begin{array}{c}\text { Areia }(\mathrm{kg} \\
794,43 \\
\end{array}$} & \multicolumn{2}{|c|}{ Brita (kg) } & $\mathrm{a}(\mathrm{kg})$ \\
\hline 0,50 & 1,00 & \multicolumn{2}{|c|}{353,08} & & \multicolumn{2}{|c|}{1059,24} & 76,5 \\
\hline \multicolumn{8}{|c|}{ Substituição de $10 \%$ (em massa de cimento) } \\
\hline Aglomerante & Areia & Brita & & a/agl. & \multicolumn{3}{|c|}{ Consumo de cimento $\left(\mathrm{Kg} / \mathrm{m}^{3}\right)$} \\
\hline 1,00 & 2,25 & 3,00 & & 0,5 & & 317 & \\
\hline \multicolumn{8}{|c|}{ Traço em massa (Substituição) } \\
\hline Traço & Adição mineral & Cimento & Areia & Brita & Água & Aditivo (\%) & $\mathrm{a} / \mathrm{c}$ \\
\hline Metacaulim & 35,31 & 317,77 & 794,43 & 1059,24 & 176,54 & 0,47 & 0,56 \\
\hline Sílica ativa & 35,31 & 317,77 & 794,43 & 1059,24 & 176,54 & 0,63 & 0,56 \\
\hline \multicolumn{8}{|c|}{ Adição de $10 \%$ (em massa de cimento) } \\
\hline Aglomerante & Areia & Brita & & a/agl. & \multicolumn{3}{|c|}{ Consumo de cimento $\left(\mathrm{Kg} / \mathrm{m}^{3}\right)$} \\
\hline 1,00 & 2,05 & 2,73 & & 0,5 & & 348 & \\
\hline \multicolumn{8}{|c|}{ Traço em Massa (Adição) } \\
\hline Traço & Adição mineral & Cimento & Areia & Brita & Água & Aditivo (\%) & $\mathrm{a} / \mathrm{c}$ \\
\hline Metacaulim & 34,82 & 348,20 & 783,46 & 1044,61 & 191,50 & 0,28 & 0,55 \\
\hline Sílica ativa & 34,75 & 347,51 & 781,92 & 1042,56 & 191,13 & 0,40 & 0,55 \\
\hline
\end{tabular}


Figura 1 - Esquema de leitura de profundidade de carbonatação

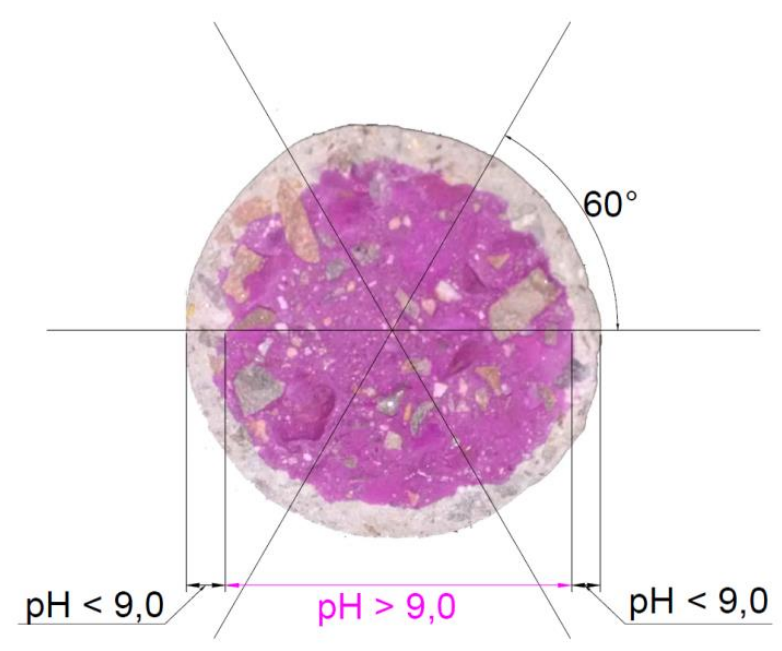

Figura 2 - Profundidade de carbonatação em função da raiz do tempo

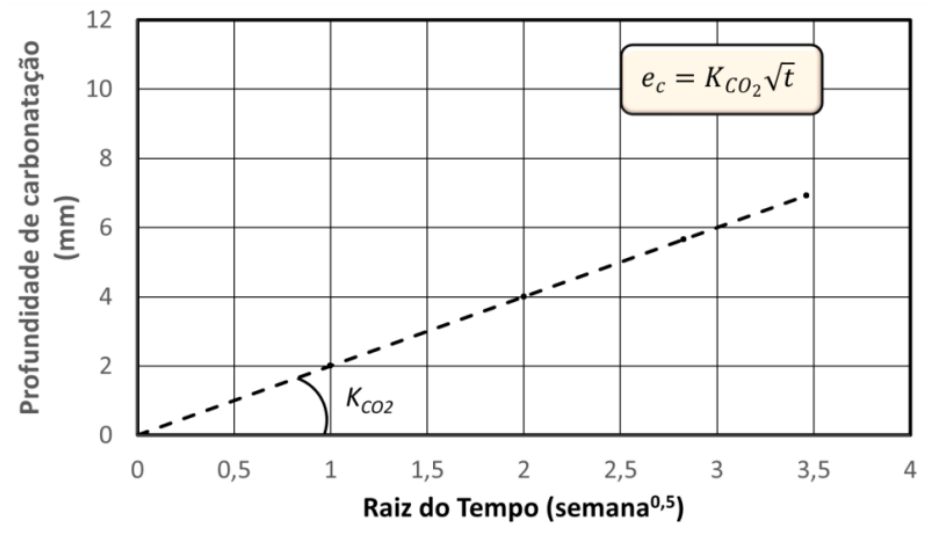

\section{Absorção de água por sucção capilar}

Este ensaio foi conduzido de acordo com a NBR 9779 (ABNT, 2012), com exceção da temperatura de secagem em estufa de $100{ }^{\circ} \mathrm{C}$, que não foi adotada por se considerar que pode alterar os compostos formados na hidratação do cimento e gerar micro fissuras no concreto. Desse modo, antes do ensaio, os corpos de prova cilíndricos de $\emptyset 10 \mathrm{x}$ $20 \mathrm{~cm}$ foram secos em estufa, à temperatura de 65 $\pm 3{ }^{\circ} \mathrm{C}$, até a constância de massa. Posteriormente, foram resfriados à temperatura de $23 \pm 2{ }^{\circ} \mathrm{C}$ e as massas secas, em gramas, determinadas. $\mathrm{O}$ ensaio de absorção por sucção capilar consistiu em colocar os corpos de prova com uma de suas faces circulares em contato com uma película de $5 \mathrm{~mm}$ de água. No procedimento, a absorção de água ocorre apenas pela face circular dos corpos de prova e a medida consiste, basicamente, na pesagem dos corpos de prova ao longo do tempo de exposição ao contato com a lâmina de água. A massa dos corpos de prova foi medida nos intervalos de 3, 6, 24, 48 e 72 horas, sendo previamente enxugados para que a água superficial não seja considerada. A absorção por sucção capilar é a diferença de massa em relação à massa seca, dividida pela área de exposição do corpo de prova, em centímetros quadrados. Após cada pesagem, os corpos de prova eram novamente expostos à lâmina de água até a realização da pesagem final do ensaio.

Como resultado de análise deste ensaio foi utilizada a sorvidade dos concretos, estabelecida por meio do procedimento proposto pela TC 116-PCD(RILEM, 1988). De forma geral, para a obtenção da sorvidade, há que se linearizar a relação entre a absorção capilar de água e o tempo, o que ocorre quando o eixo das abscissas passa a ser expresso na forma da raiz quadrada do tempo, Figura 3. 
Figura 3 - Representação da sorvidade e absorção inicial

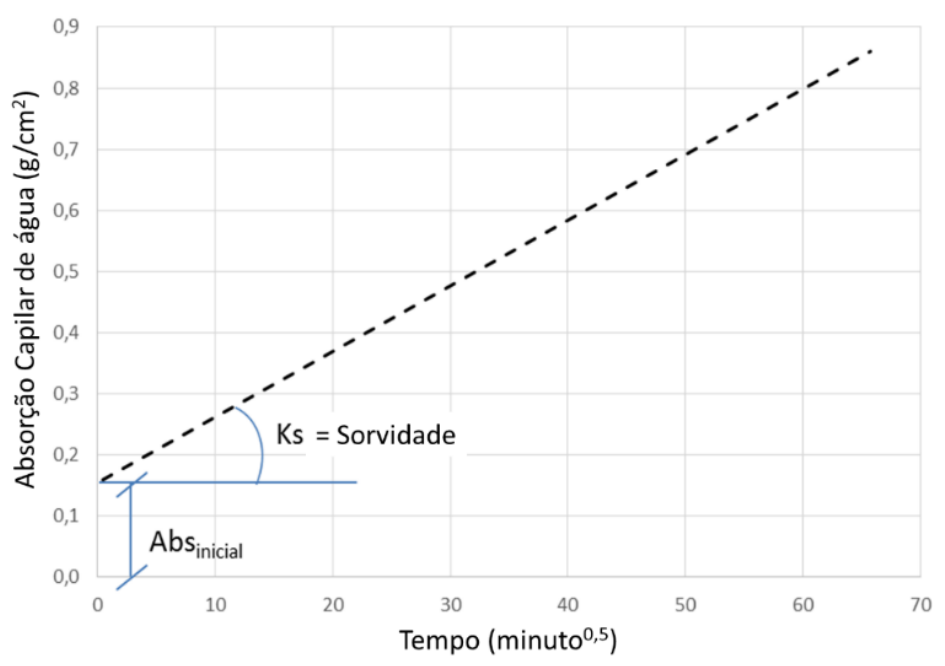

A representação linearizada da absorção capilar de água resulta em uma equação de $1^{\circ}$ grau, em que o coeficiente angular representa a sorvidade do material, expressa em $\mathrm{g} /\left(\mathrm{cm}^{2} \cdot\right.$ minuto $\left.^{0,5}\right)$. Assim sendo, a sorvidade passa a ser uma característica intrínseca do material testado e, dessa forma, permite a análise comparativa entre diferentes composições cimentícias utilizadas na execução de concretos.

\section{Difratometria de raios X (DRX)}

Esta técnica foi usada em dois momentos do trabalho: 1) identificação de compostos mineralógicos e halo amorfo das adições no estado anidro; 2) comparação da intensidade de pico de portlandita nas argamassas extraídas dos cinco concretos estudados, na idade de 126 dias (compósito curado em $95 \pm 5 \%$ de umidade relativa e temperatura de $23 \pm 2{ }^{\circ} \mathrm{C}$ até os 28 dias e acondicionados em ambiente com $55 \pm 3 \%$ de umidade relativa e temperatura de $23 \pm 2{ }^{\circ} \mathrm{C}$ ).

As amostras das argamassas dos concretos foram retiradas com o auxílio de marreta e talhadeira, posteriormente moídas com pistilo em almofariz, ambos cerâmicos, e, na sequência, secas em microondas durante $9 \mathrm{~min}$, conforme as recomendações de Cabrera e Rojas (2001). Após a secagem, as amostras foram armazenadas em Eppendorf de 2 $\mathrm{mL}$ e estocadas em recipiente polimérico contendo sílica gel até a realização dos ensaios.

As amostras das adições no estado anidro e das argamassas moídas foram preparadas por prensagem manual no porta-amostra e expostas aos raios X no equipamento RIGAKU Ultima IV X-ray diffractometer. A análise foi realizada entre $5^{\circ}$ e $75^{\circ}$ $2 \theta$, com passo angular de $0,02^{\circ} 2 \theta$ e tempo por passo de $1 \mathrm{~s}$. A análise utilizou tubo com ânodo de cobre, $40 \mathrm{kV} / 30 \mathrm{~mA}$ e fenda divergente de $1^{\circ}$.

\section{Sobre o estudo em argamassa extraída do concreto}

De acordo com Nita e John (2007), na hidratação do cimento Portland sem pozolana a intensidade dos picos de portlandita aumentam com o decorrer da hidratação da alita e belita, desde que não ocorra carbonatação. Em uma pasta de cimento com pozolana, parte ou todo o hidróxido de cálcio é consumido por reações com a pozolana, o que normalmente provoca uma redução na intensidade dos picos correspondentes. Apesar de fatores de influência como grau de cristalinidade e variações na orientação dos cristais durante a preparação de amostras, a variação da intensidade dos picos de portlandita no DRX para o estudo de pozolanas está relacionada com a sua quantidade no compósito cimentício (NITA, 2006). Voglis, Kakali e Tsilvilis (2001), Antiohos et al. (2007), Cabral (2011), Dantas (2013), Picanço, Angélica e Barata (2014), Vaitkevicius, Serelis e Hilbig (2014), GómezZamorano, García-Guillén e Acevedo-Dávila (2015), Abo-El-Enein et al. (2015) e Silva (2016) também usaram o raciocínio de comparação de intensidade de picos para o estudo de pozolanas, assim como também realizado em outros trabalhos dentro do grupo de pesquisa deste artigo, podendose exemplificar as publicações de Gobbi (2014), Raisdorfer (2015) e Medeiros et al. (2015).

Dentro desse contexto, a técnica de difração de raios $\mathrm{X}$ foi aplicada em amostras da argamassa dos concretos e a avaliação teve como foco comparar a intensidade do principal pico relativo à portlandita (localizado na região de $34,2^{\circ} \quad 2 \theta$ nos difratogramas). A análise se baseou na premissa de que, mantendo as mesmas condições de ensaio de 
DRX, a redução da intensidade do pico referente à portlandita nas argamassas dos concretos contendo adições minerais em comparação ao mesmo pico na argamassa do concreto de referência indica menor teor remanescente de $\mathrm{Ca}(\mathrm{OH})_{2}$ nos concretos. Dessa forma, as análises utilizaram uma pequena porção do difratograma gerado no ensaio de DRX, como ilustrado na Figura 4. Essa é uma avaliação puramente qualitativa, e não apresenta a pretensão de quantificar o teor de portlandita em cada concreto estudado.

\section{Chapelle modificado}

O ensaio Chapelle modificado é um método de medida da atividade pozolânica por meio da determinação do teor de hidróxido de cálcio fixado. Esse método é normalizado no Brasil de acordo com a NBR 15895 (ABNT, 2010) e o seu resultado é expresso pela quantidade de hidróxido de cálcio consumido ou fixado por grama de material pozolânico ( $\mathrm{mg} \mathrm{Ca}(\mathrm{OH})_{2} / g$ pozolana).

O método Chapelle modificado permite determinar a pozolanicidade de uma adição mineral, na sua finura de utilização, pela taxa de reação da cal, após um tempo padronizado, sendo a reação acelerada por elevação da temperatura, ou seja, uma determinada quantidade de material supostamente pozolânico (1 grama) e de óxido de cálcio (2 gramas) são colocados para reagir em banho-maria $\left(90 \pm 5^{\circ} \mathrm{C}\right)$. A mistura é mantida reagindo por $16 \mathrm{~h}$. A cal consumida é calculada pela diferença entre a cal adicionada e a cal remanescente após o ensaio.
A pozolanicidade do material é admitida quando o consumo de óxido de cálcio é superior a $330 \mathrm{mg}$ $\mathrm{CaO} / \mathrm{g}$ pozolana que, por estequiometria, corresponde a $436 \mathrm{mg} \mathrm{Ca}(\mathrm{OH})_{2} / g$ pozolana.

\section{Caracterização dos aglomerantes}

O foco deste trabalho é investigar o efeito do metacaulim e da sílica ativa na velocidade de carbonatação do concreto. O cimento do tipo CP V - ARI, com massa específica média de $3,09 \mathrm{~g} / \mathrm{cm}^{3}$, foi utilizado neste estudo por representar o aglomerante comercializado nacionalmente que contém o menor teor de adição mineral incorporado à sua composição. A Tabela 2 indica as características físicas e propriedades mecânicas desse cimento.

A Tabela 3 mostra a análise química por fluorescência de raios $\mathrm{X}$ do $\mathrm{CP} \mathrm{V}-\mathrm{ARI}$ e das adições pozolânicas.

A Tabela 4 mostra a área específica medida por BET que indica que as duas adições apresentam finura muito superior ao cimento $\mathrm{CP} \mathrm{V}$.

A Figura 5 apresenta os difratogramas do metacaulim e da sílica ativa. No metacaulim foram identificados picos característicos de quartzo, caulinita $\left(\mathrm{Al}_{2} \cdot \mathrm{Si}_{2} \cdot \mathrm{O}_{5} \cdot(\mathrm{OH})_{4}\right)$ e muscovita (K. $\left.\mathrm{Al}_{2} \cdot\left(\mathrm{Al} \cdot \mathrm{Si}_{3} \cdot \mathrm{O}_{10}\right) \cdot(\mathrm{OH})_{2}\right)$, além da presença de estrutura amorfa, representada pelo halo difuso no difratograma, constituída basicamente por sílica e alumina sem arranjo atômico característico, como também constatado por Medina (2011).

\section{Figura 4 - Difratograma da amostra de argamassa extraída do concreto de referência}

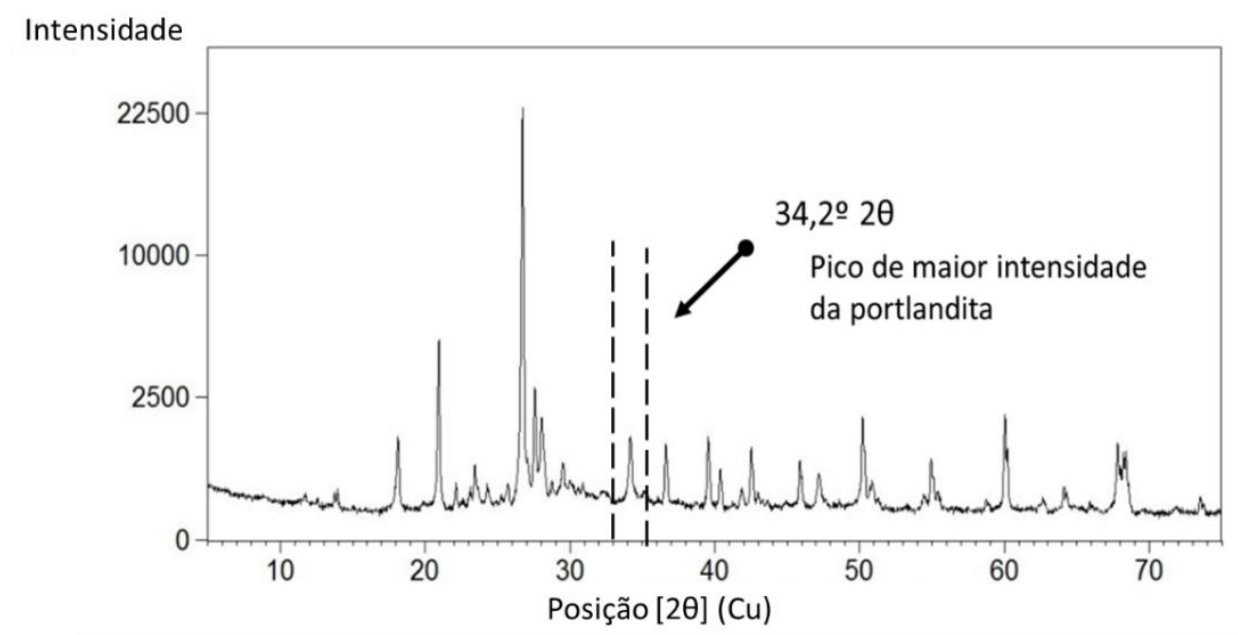

Tabela 2 - Caracterização física e mecânica do cimento Portland CP V - ARI

\begin{tabular}{|c|c|c|c|c|c|c|c|c|c|c|}
\hline \multicolumn{7}{|c|}{$\overline{\text { Análise física }}$} & \multicolumn{4}{|c|}{ Análise mecânica } \\
\hline $\begin{array}{c}\text { Expansão } \\
\text { Quente } \\
(\mathrm{mm})\end{array}$ & $\begin{array}{c}\text { Início } \\
\text { Pega } \\
\text { (h) }\end{array}$ & $\begin{array}{l}\text { Fim } \\
\text { Pega } \\
\text { (h) }\end{array}$ & $\begin{array}{l}\text { Consistência } \\
\text { Normal (\%) }\end{array}$ & $\begin{array}{c}\text { Blaine } \\
(\mathrm{cm} 2 / \mathrm{g})\end{array}$ & $\begin{array}{c}\# 200 \\
(\%)\end{array}$ & $\begin{array}{c}\# 325 \\
(\%)\end{array}$ & $\begin{array}{l}1 \text { dia } \\
\text { (MPa) }\end{array}$ & $\begin{array}{l}3 \text { dias } \\
(\mathrm{MPa})\end{array}$ & $\begin{array}{l}7 \text { dias } \\
(\mathrm{MPa})\end{array}$ & $\begin{array}{l}28 \text { dias } \\
\text { (MPa) }\end{array}$ \\
\hline 0,50 & $02: 20$ & 03:00 & 28 & 4,130 & 0,40 & 3,60 & 22,5 & 34,8 & 42,00 & 48,8 \\
\hline
\end{tabular}


Tabela 3 - Análise química, por fluorescência de raios $X$, do cimento CP V-ARI e das pozolanas

\begin{tabular}{c|cccccccccccccccc}
\hline \multirow{2}{*}{\begin{tabular}{c} 
Amostras \\
\cline { 2 - 15 }
\end{tabular}} & $\mathrm{SiO}_{2}$ & $\mathrm{~K}_{2} \mathrm{O}$ & $\mathrm{Fe}_{2} \mathrm{O}_{3}$ & $\mathrm{CaO}$ & $\mathrm{Al}_{2} \mathrm{O}_{3}$ & $\mathrm{P}_{2} \mathrm{O}_{5}$ & $\mathrm{TiO}_{2}$ & $\mathrm{SO}_{3}$ & $\mathrm{MgO}$ & $\mathrm{ZnO}$ & $\mathrm{MnO}$ & $\mathrm{CuO}$ & $\mathrm{Rb}_{2} \mathrm{O}$ & $\mathrm{Tm}_{2} \mathrm{O}_{3}$ & $\mathrm{SrO}$ \\
\hline $\begin{array}{c}\text { Cimento } \\
\text { CPV-ARI }\end{array}$ & 10,45 & 1,36 & 3,71 & 73,21 & 3,59 & - & 0,26 & 3,05 & 3,66 & 0,02 & 0,14 & - & - & 0,11 & 0,43 \\
\hline Metacaulim & 45,86 & - & 3,90 & 0,14 & 46,05 & - & 2,22 & 1,69 & - & 0,01 & 0,01 & 0,01 & 0,01 & - & 0,01 \\
\hline Sílica ativa & 92,49 & 2,76 & 0,13 & 0,51 & 1,91 & - & - & 2,08 & - & 0,02 & 0,07 & 0,02 & 0,01 & - & - \\
\hline
\end{tabular}

Tabela 4 - Área específica BET dos aglomerantes

\begin{tabular}{c|c}
\hline Aglomerante & Área específica BET $\left(\mathbf{m}^{2} / \mathbf{k g}\right)$ \\
\hline Cimento CPV-ARI & 1.070 \\
Metacaulim & 23.259 \\
Sílica ativa & 20.238 \\
\hline
\end{tabular}

Figura 5 - Perfis difratométricos das amostras de adições pozolânicas
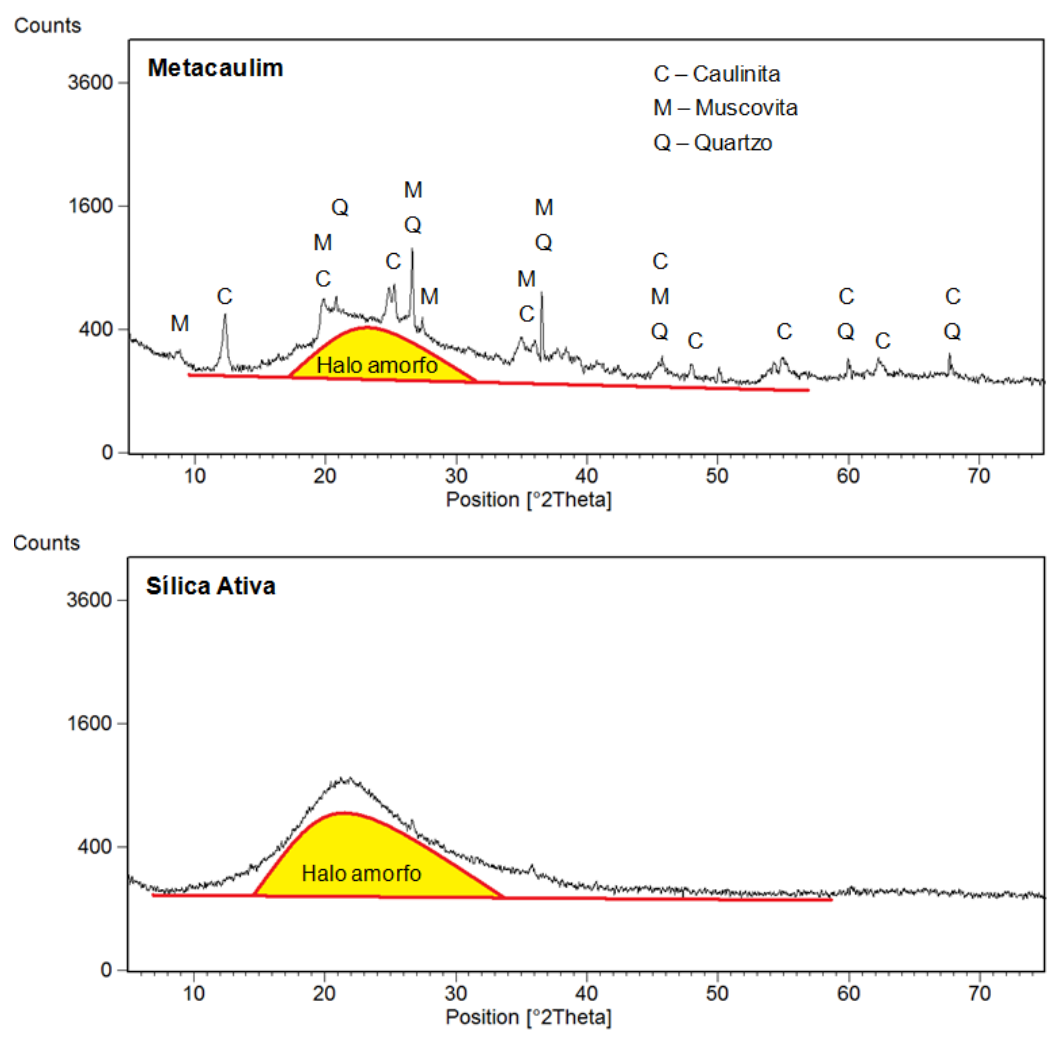

O difratograma da sílica ativa indica que o material é totalmente amorfo (vítreo), com a ocorrência do halo amorfo característico de materiais pozolânicos de base silicosa.

O ensaio de pozolanicidade das duas adições com o método Chapelle modificado, conduzido em conformidade com a NBR 15895 (ABNT, 2010), apresentou o resultado de 1.193 e $1.542 \mathrm{mg}$ $\mathrm{Ca}(\mathrm{OH})_{2} / \mathrm{g}$ de pozolana para o metacaulim e sílica ativa, respectivamente. Esses valores são muito superiores ao limite de $436 \mathrm{mg} \mathrm{Ca}(\mathrm{OH})_{2} / \mathrm{g}$ de pozolana, indicado na norma brasileira, o que confirma a elevada capacidade de reação dessas duas pozolanas.

\section{Resultados e discussão}

\section{Estudo da portlandita remanescente usando DRX}

A Figura 6 apresenta as análises comparativas no que tange à substituição e à adição de $10 \%$ de metacaulim e sílica ativa sobre o cimento, respectivamente. Esta imagem indica redução da intensidade de pico principal de portlandita nos casos de emprego de metacaulim e de sílica ativa. 
Figura 6 - Difratogramas parciais, com ênfase na região de localização do principal pico da portlandita $\left(34,2^{\circ} \theta\right)$, das argamassas do concreto de cimento CP V - ARI e dos concretos com a utilização, por adição ou substituição parcial de cimento, de metacaulim e sílica ativa

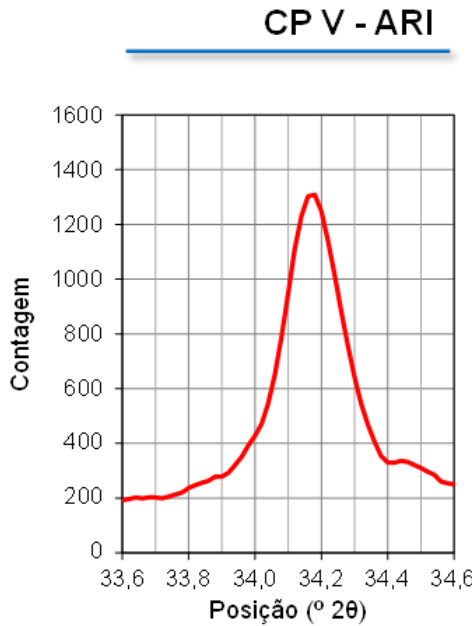

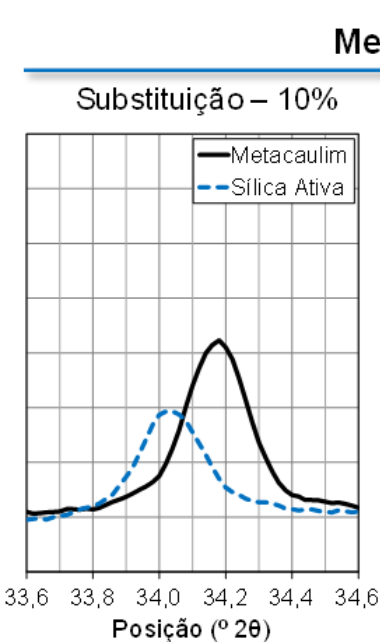

Metacaulim e Sílica Ativa

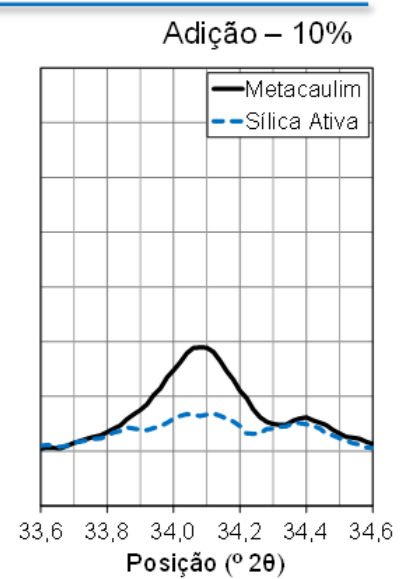

Os difratogramas indicaram que o uso de metacaulim e sílica ativa em adição ao cimento propiciou maior consumo de portlandita do que o uso como substituição parcial, o que resultou em menor intensidade de pico principal de portlandita. A justificativa para esse comportamento está baseada na maior atividade pozolânica quando há maior disponibilidade de cal no sistema, ou seja, quando a relação pozolana/portlandita é reduzida, há uma tendência a maior consumo de portlandita pela pozolana. O trabalho de Quarcioni et al. (2015) apresenta resultados de capacidade de fixação de cal de diferentes pozolanas, determinados por meio do ensaio Chapelle modificado utilizando as relações óxido de cálcio $(\mathrm{CaO})$ /pozolana, em massa, igual a 1,0 e 2,0. No caso do metacaulim e da sílica ativa, os autores concluíram que a maior disponibilidade de cal propicia maior teor de cal fixado pela pozolana.

Apesar da técnica de DRX ter sido usada neste trabalho de forma qualitativa, a análise comparativa serve de indicativo de tendência de comportamento. A Figura 6 indica que a sílica ativa apresentou, ao ser caracterizada, maior capacidade de fixar cal quando comparada ao metacaulim, que corrobora o resultado obtido no Chapelle modificado.

\section{Resistência à compressão}

A Figura 7 apresenta os resultados de resistência à compressão dos concretos. Nos casos em que houve a substituição parcial de cimento, em teor de $10 \%$, em massa, os valores de resistência à compressão foram $15 \%$ e $13 \%$ superiores em relação à série de referência para o metacaulim e para a sílica ativa, respectivamente. No caso da adição das pozolanas ao cimento, tanto o metacaulim como a sílica ativa propiciaram elevação da resistência em comparação ao concreto de referência, atingindo, em média, 78 $\mathrm{MPa}$ (incremento de $42 \%$ ) e $70 \mathrm{MPa}$ (incremento de $27 \%$ ), respectivamente. Em todos os casos, foi comprovado pelo teste de Tukey de comparação de médias (considerando um intervalo de confiança de 95\%) que as médias da Figura 7 são diferentes entre si, com exceção das séries de substituição parcial por metacaulim e sílica ativa que são iguais entre si.

Esse nível de elevação da resistência à compressão também foi encontrado nos estudos de TorresAgredo, Mejía-de-Gutiérrez e Delvasto-Arjona (2011), Gutiérrez et al. (2009) e Medeiros et al. (2012), e o motivo é o refinamento dos poros do concreto provocado pelas reações pozolânicas (POON; KOU; LAM, 2006).

\section{Carbonatação acelerada e sorvidade}

A Figura 8 apresenta o efeito das adições pozolânicas na velocidade de carbonatação por meio do coeficiente de carbonatação $\left(\mathrm{K}_{\mathrm{CO}_{2}}\right)$. Os resultados indicam que a sílica ativa usada como adição de $10 \%$ reduziu a velocidade de carbonatação; porém, quando usada como substituição parcial de cimento Portland, no mesmo teor, tornou o concreto mais susceptível ao avanço da carbonatação em comparação à série de referência. $\mathrm{O}$ comportamento de aumento do coeficiente de carbonatação em decorrência da substituição parcial de cimento também foi constatado no caso do metacaulim, com a mesma magnitude de efeito da sílica ativa. O metacaulim, utilizado como adição, reduziu em $8,0 \%$ a velocidade de carbonatação, eficiência muito inferior ao observado na sílica ativa, com redução de $69 \%$. 
Figura 7 - Resistência à compressão das diferentes séries de concretos do experimento

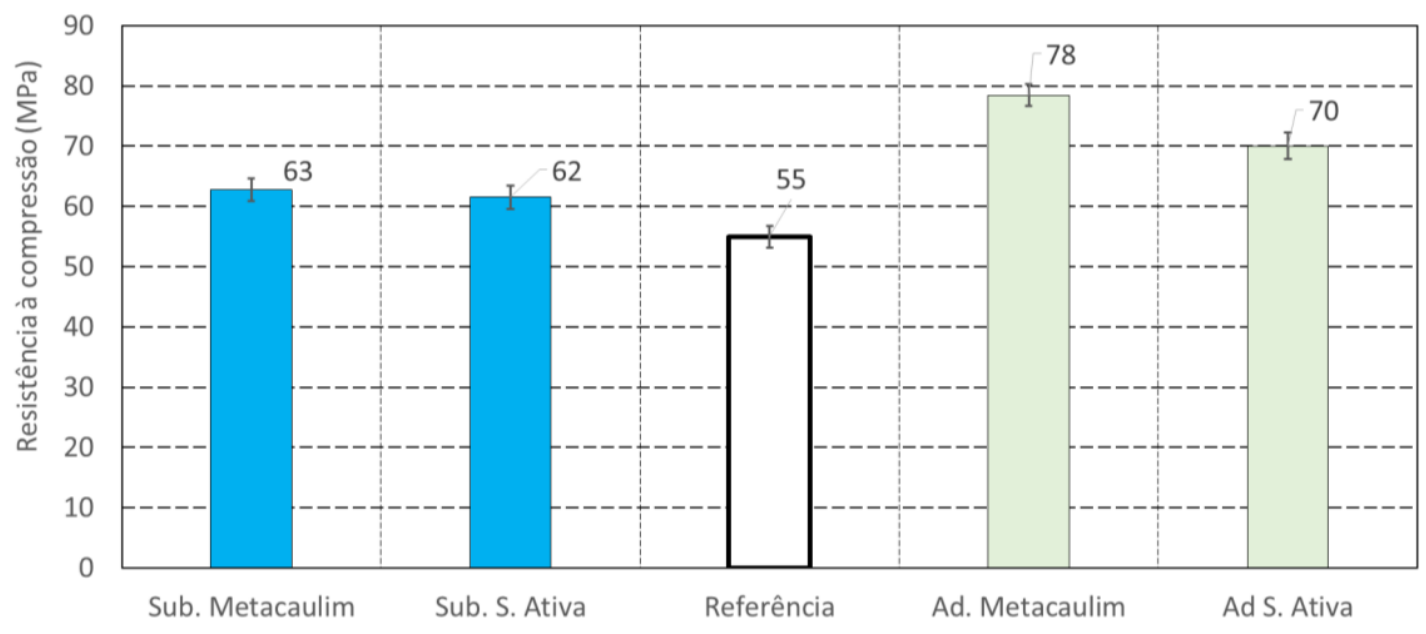

O uso das adições como substituição parcial tende a reduzir a reserva alcalina, como evidenciado na Figura 6, e isso explica a tendência de aumento da velocidade de carbonatação nesses concretos.

Pessôa e Nepomuceno (2002) e Mehta e Monteiro (2008) argumentam, fundamentados em dados experimentais, que o maior consumo de cimento do concreto tende a reduzir a velocidade de carbonatação, comparando concretos de mesma relação água/aglomerantes. Nos dados desta pesquisa, para o emprego do metacaulim e da sílica ativa como adição existe uma mudança no traço unitário, como indicado na Tabela 1, o que resulta em mais cimento por metro cúbico de concreto. Isso significa que no concreto existe mais portlandita por unidade de volume de concreto se comparado com a série com uso por substituição, ou seja, a reserva alcalina é maior. $\mathrm{Na}$ atuação de uma pozolana existem efeitos contrários em termos de carbonatação: por um lado ela causa o refinamento dos poros e a redução da sua interconectividade (refletido na Figura 9); por outro lado ocorre a redução da reserva alcalina (refletido na Figura 6). Para o uso como adição, o efeito de refinamento dos poros parece ter sido predominante, o que compensa o efeito da redução da reserva alcalina.

Os trabalhos de Papadakis (2000) e Bucher, Cyr e Escadeillas (2015), o primeiro sobre sílica ativa e o segundo sobre o metacaulim, indicam também a tendência ao aumento da velocidade de carbonatação com o emprego das duas adições desse experimento (em substituição parcial do cimento Portland), e o motivo é o consumo de portlandita pela reação pozolânica.

É importante enfatizar que o teste de Tukey foi usado para a comparação de médias da Figura 8 , com $95 \%$ de significância, e pode-se afirmar que apenas são estatisticamente equivalentes os pares de médias "Ad. Metacaulim x Referência" e "Sub. S. Ativa x Sub. Metacaulim".

A Figura 9 apresenta o efeito das adições pozolânicas na sorvidade dos concretos em uma tentativa de usar esse parâmetro, relacionado à porosidade, como meio de explicar o aumento na velocidade de carbonatação ocorrido nos casos em que houve a substituição parcial do cimento por metacaulim e sílica ativa.

Para o uso das adições como substituição parcial do cimento Portland, a sílica ativa causou redução de $10 \%$ na sorvidade e o metacaulim não apresentou diferença estatística do resultado em relação à série de referência. Quando utilizada em adição ao cimento, o metacaulim e a sílica ativa reduzem a capacidade do concreto em absorver água em 12\% e $46 \%$, respectivamente, comparados à série de referência.

Deve-se destacar que o teste de Tukey foi usado na comparação de médias da Figura 9 com $95 \%$ de significância, e pode-se afirmar que apenas são estatisticamente equivalentes os pares de médias "Ad. Metacaulim x Sub S. ativa" e "Referência x Sub. Metacaulim". 
Figura 8 - Variação do coeficiente de carbonatação dos concretos em decorrência da utilização de metacaulim ou sílica ativa em adição ou substituição parcial ao cimento

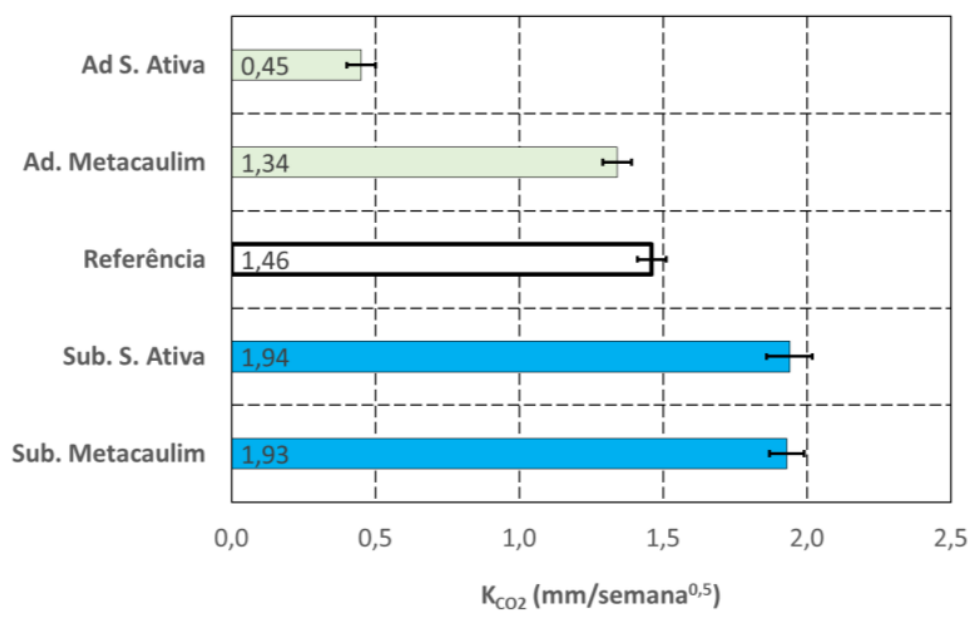

Figura 9 - Efeito do metacaulim e sílica ativa na sorvidade dos concretos

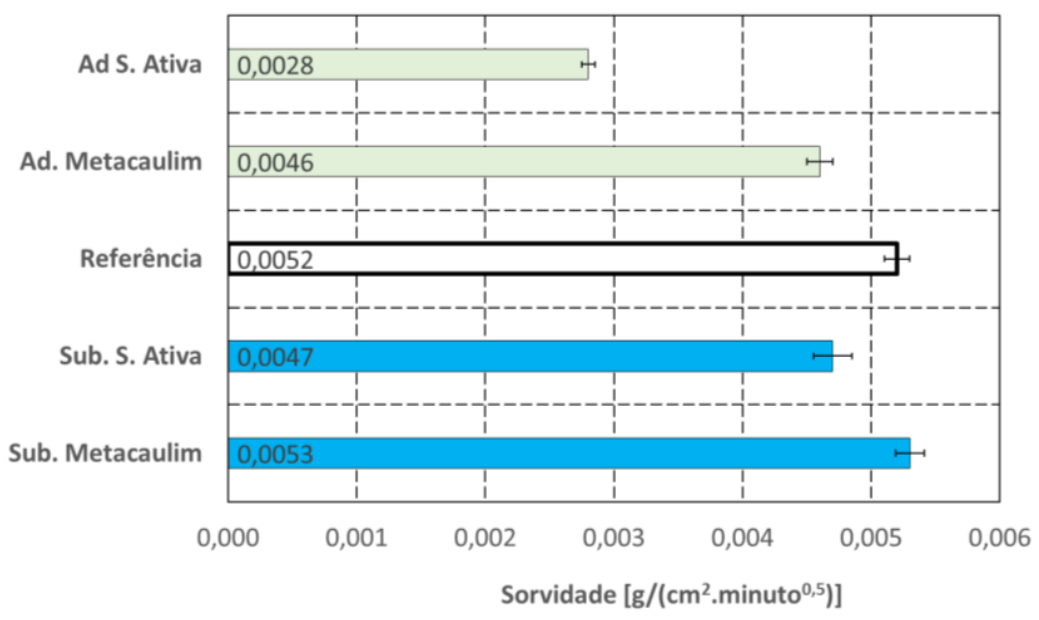

\section{Correlação entre os resultados com $\mathrm{KCO}_{2}$}

A partir dos dados obtidos experimentalmente foram realizadas algumas correlações entre os resultados para entender os fatores de influência nos dados de carbonatação do concreto, principal variável de resposta desta pesquisa. A primeira análise, apresentada na Figura 10, relacionou o coeficiente de carbonatação em função da resistência à compressão e da sorvidade, obtendo-se coeficientes de determinação $\left(R^{2}\right)$ iguais a 0,19 e 0,74 , respectivamente. Os valores de $\mathrm{R}^{2}$ indicam que o coeficiente de carbonatação apresenta pequena dependência da resistência à compressão e satisfatória relação com a sorvidade. No que tange à resistência à compressão, o resultado obtido está de acordo com as pesquisas de Hoppe Filho et al. (2013) e Medeiros Júnior et al. (2014), os quais evidenciaram que a resistência à compressão não está diretamente relacionada à durabilidade do material em condições de uso. Para a sorvidade, relacionada à absorção capilar de água, porosidade e interconexão entre poros, observa-se uma relação diretamente proporcional com o coeficiente de carbonatação. Esse comportamento se justifica em função da dependência da absorção capilar de água e da difusão do anidrido carbônico (frente de carbonatação) com a rede capilar de poros interconectados e acessíveis na superfície do concreto.

De fato, é de interesse tecnológico abranger a resistência à compressão no entendimento da carbonatação do concreto, o que se apresentou, em um primeiro momento, de forma insatisfatória. Assim sendo, há que se compor um índice que contemple a resistência à compressão do concreto em associação com outra característica intrínseca do mesmo material que, no presente caso, passa a ser a sorvidade. 
Figura 10 - Relação entre os coeficientes de carbonatação versus resistência à compressão e sorvidade dos concretos

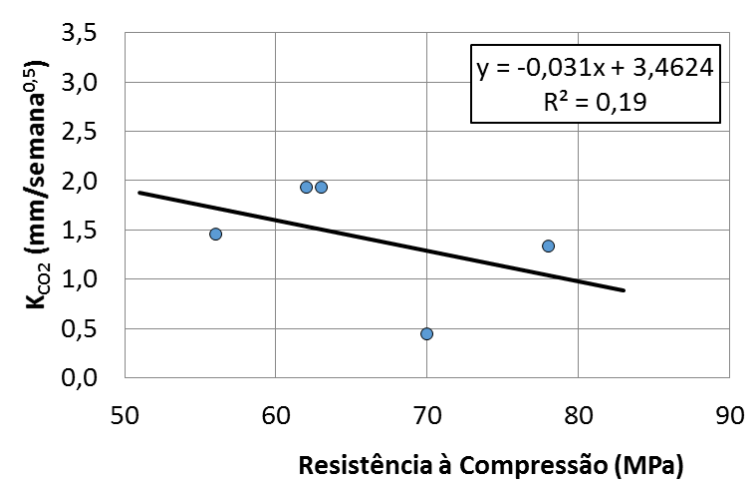

O índice proposto contempla a relação entre a sorvidade e a resistência à compressão, conforme apresentado na Equação 2. A sorvidade, por ser diretamente relacionada ao coeficiente de carbonatação, foi considerada no numerador, e a resistência à compressão, inversamente proporcional, no denominador.

$K_{\text {sorvidade } / f c}=\frac{\text { Sorvidade }\left(\frac{g}{\text { cm }^{2} \cdot \text { minuto }}, 0,5\right.}{\text { Resistência à compressão }(M P a)}$ Eq. 2

A Figura 11 apresenta a relação entre o coeficiente de carbonatação e o índice proposto.

$\mathrm{O}$ coeficiente de determinação $\left(\mathrm{R}^{2}\right)$ obtido foi de 0,64 , o que indica que a dependência entre as variáveis envolvidas é menor do que a simples correlação com a sorvidade que teve $\mathrm{R}^{2}$ de 0,74 . Esse é um indício de que o $\mathrm{K}_{\text {sorvidade/fc }}$ não explica melhor o processo de carbonatação do que um simples ensaio de absorção de água por capilaridade.

Na sequência foi realizada uma segunda tentativa de correlação com um coeficiente que se relacione melhor com $\mathrm{K}_{\mathrm{CO} 2}$ e optou-se por inserir no índice anteriormente proposto a relação água/cimento efetiva dos concretos, já que a relação água/aglomerante foi mantida constante. Assim sendo, o novo índice foi determinado conforme apresentado na Equação 3.

$K_{(\text {sorvidade.a/c) } / f c}=\frac{\text { Sorvidade }\left(\frac{g}{c m^{2} \cdot \text { minuto } 0,5}\right) \cdot a / c}{\text { Resistência à compressão }(M P a)}$

A Figura 12 apresenta a relação entre o coeficiente de carbonatação e o novo índice proposto.

A Figura 12 indica que o índice que contempla a sorvidade, a relação $\mathrm{a} / \mathrm{c}$ e a resistência à compressão, parâmetros característicos de cada concreto, apresentou elevada relação com o coeficiente de carbonatação. O coeficiente de determinação $\left(\mathrm{R}^{2}\right)$ obtido, igual a 0,85 , indica que há boa correlação entre as variáveis envolvidas, ou

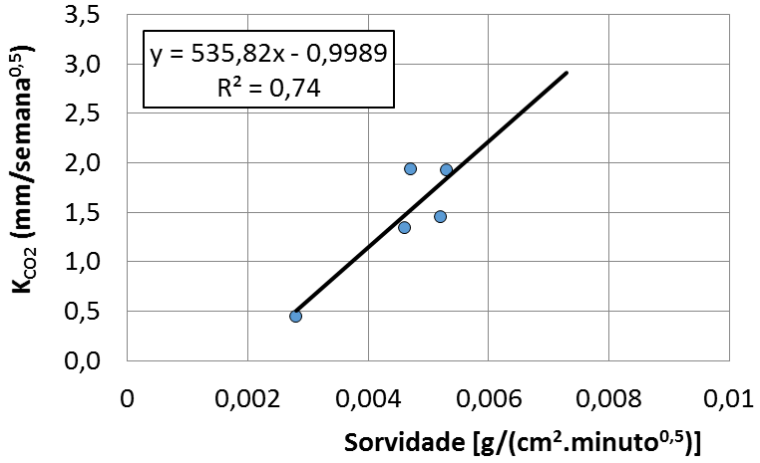

seja, as características intrínsecas dos concretos utilizadas no índice proposto exercem significativa influência na carbonatação desses concretos. Desse modo, ficou evidente que o $\mathrm{K}_{\text {(sorvidade.a/c)/fc }}$ apresenta correlação mais efetiva com o $\mathrm{K}_{\mathrm{CO} 2}$ do que todas as outras tentativas de estabelecer relação entre os resultados, o que indica que houve uma elevação da capacidade do modelo em explicar a velocidade de carbonatação dos concretos desse experimento.

A generalização do índice proposto neste trabalho a outros concretos deve ser avaliada em outras pesquisas a fim de validar sua representatividade. Contudo, a ideia de testar a validade do modelo é útil porque este pode ser uma forma de viabilizar estimativas da capacidade de proteção quanto à carbonatação sem necessariamente executar um ensaio de carbonatação acelerada, o qual é oneroso, demorado e envolve infraestrutura que existe em poucos laboratórios nacionais.

\section{Conclusões}

As conclusões desta pesquisa estão apresentadas a seguir:

(a) a aplicação de metacaulim e sílica ativa como substituição parcial do cimento Portland, em teor de $10 \%$, causa aumento da velocidade de carbonatação do concreto. Nesse experimento, o aumento na velocidade de carbonatação provocado por essas adições pozolânicas foi de $32 \%$;

(b) a sílica ativa reduz a velocidade de carbonatação quando empregada como adição, por outro lado causa aumento da velocidade de carbonatação quando usada em substituição parcial ao cimento Portland, em teor de $10 \%$;

(c) o metacaulim apresentou um comportamento semelhante ao da sílica ativa; porém, no caso de emprego como adição de $10 \%$ teve menor capacidade de redução do coeficiente de carbonatação, causando redução de apenas $8 \%$; 
(d) o emprego de metacaulim e sílica ativa causou pequena variação na absorção de água por sucção capilar em todos os casos de uso dessas pozolanas, exceto no caso da sílica ativa que, quando utilizada em adição ao cimento, reduziu a absorção capilar de água em 46\%;

(e) o uso da pozolana como adição modifica o traço do concreto em massa, resultando em maior quantidade de aglomerante por unidade de volume de concreto. Isso gera maior reserva alcalina do que o caso de uso como substituição, e, por isso, a velocidade de carbonatação tende a ser menor para o emprego da pozolana como adição; e

(f) a resistência à compressão, a absorção de água por sucção capilar e a relação água/cimento apresentam influência na velocidade de carbonatação e, quando relacionadas ao coeficiente de carbonatação por meio de um índice que considere a influência conjunta dessas grandezas, apresentam elevada representatividade. Um exemplo disso é o coeficiente proposto neste trabalho, designado como $\mathrm{K}_{\text {(sorvidade.a/c)/fb }}$ com $\mathrm{R}^{2}$ igual a 0,85 .

Figura 11 - Relação entre o índice que relaciona a sorvidade e a resistência à compressão em função do coeficiente de carbonatação dos concretos

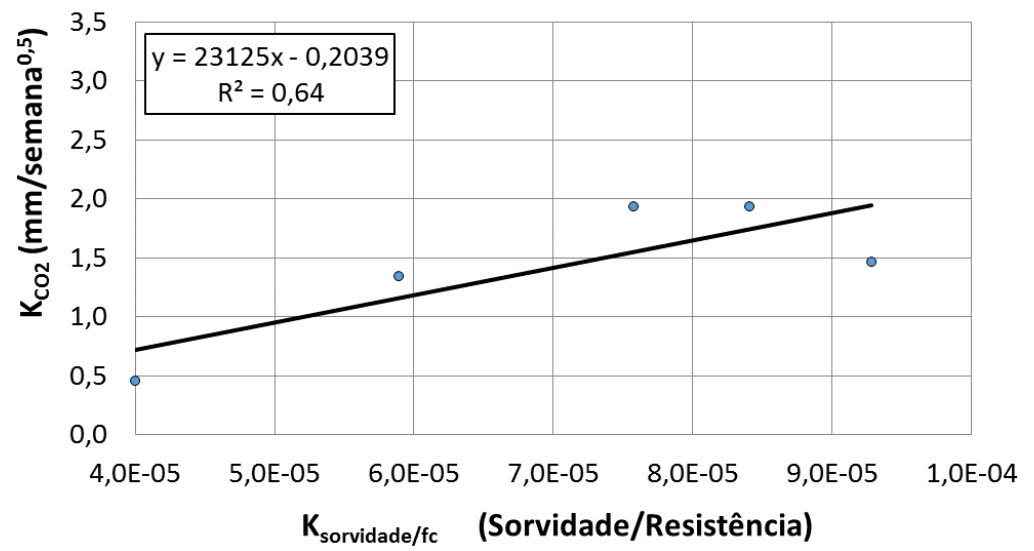

Figura 12 - Relação entre o índice que relaciona a sorvidade, a relação a/c e a resistência à compressão em função do coeficiente de carbonatação dos concretos

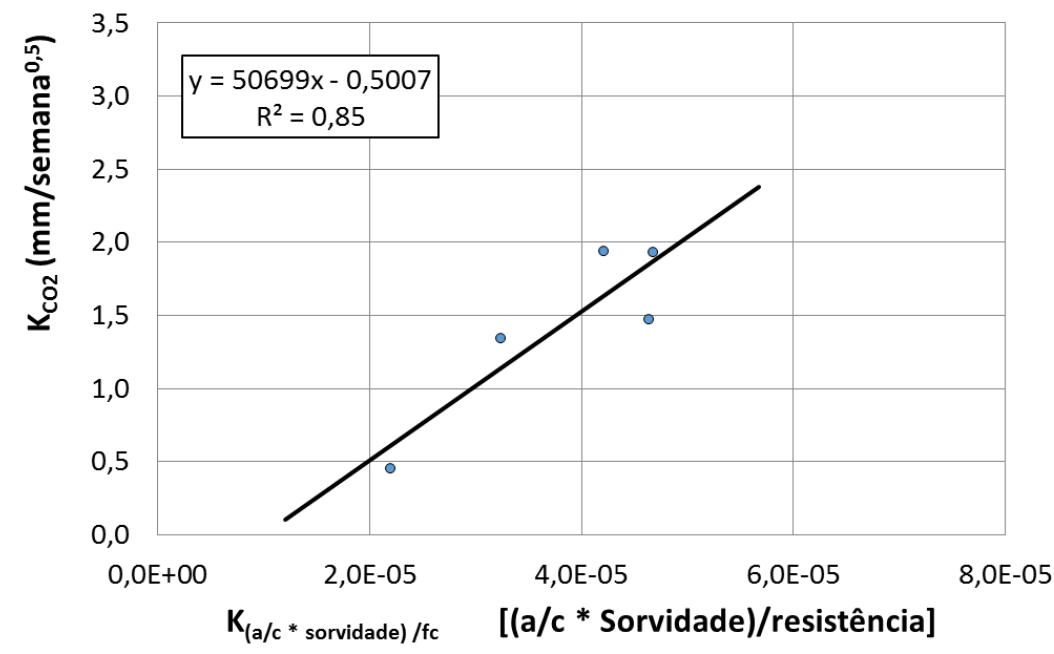


Os dados apresentados neste trabalho permitem estabelecer conclusões delineadas e restritas aos materiais utilizados na presente pesquisa. Qualquer generalização precisa ser realizada com cautela, pois o comportamento pode variar com a mudança na origem dos materiais que compõem o concreto.

\section{Referências}

ABO-EL-ENEIN, S. A. et al. Physico-Mechanical Properties of Composite Cement Pastes Containing Silica Fume and Fly ash. Housing and Building National Research Center, v. 11, p. 7-15, 2015.

ANTIOHOS, S. K. et al. Improving the Performance of Ternary Blended Cements by Mixing Different Types of Fly Ashes. Cement and Concrete Research, v. 37, p. 877-885, 2007.

ASSOCIAÇÃO BRASILEIRA DE NORMAS TÉCNICAS. NBR 15895: materiais pozolânicos: determinação do teor de hidróxido de cálcio fixado: método Chapelle modificado. Rio de Janeiro, 2010.

\section{ASSOCIAÇÃO BRASILEIRA DE NORMAS} TÉCNICAS. NBR 5738: concreto: procedimento para moldagem e cura de corpos de prova. Rio de Janeiro, 2015.

ASSOCIAÇÃO BRASILEIRA DE NORMAS TÉCNICAS. NBR 5739: concreto: ensaios de compressão de corpos de prova cilíndricos. Rio de Janeiro, 2007.

\section{ASSOCIAÇÃO BRASILEIRA DE NORMAS TÉCNICAS. NBR 9779: argamassa e concreto endurecidos: determinação da absorção de água por capilaridade. Rio de Janeiro, 2012.}

BUCHER, R.; CYR, M.; ESCADEILLAS, G. Carbonation of Blended Binders Containing Metakaolin. Calcined Clays for Sustainable Concrete, v. 10, p. 27-33, 2015.

CABRAL, K. C. Efeito da Adição de Cargas Minerais Leves na Resistência Mecânica de Grautes Para Cimentação de Poços Offshore. Natal, 2011. Tese (Doutorado em Ciência e Engenharia de Petróleo) - Universidade Federal do Rio Grande do Norte, Natal, 2011.

CABRERA, J.; ROJAS, M. F. Mechanism of Hydratation of the Metakaolin-Lime-Water System. Cement Concrete Research, v. 31, p. 177-182, 2001.

DANTAS, H. de O. Avaliação dos Efeitos da Adição de Nanossílicas em Pó e Coloidal em Pastas de Cimento Portland. Recife, 2013. Dissertação (Mestrado em Engenharia Civil e Ambiental) - Universidade Federal de Pernambuco, Recife, 2013.
GOBBI, A. Atividade Pozolânica de Adições Minerais pela NBR 5751/2012 e NBR 5752/2012: uma análise crítica a partir de métodos complementares. Curitiba, 2014. Dissertação (Mestrado em Engenharia de Construção Civil) Escola de Engenharia, Universidade Federal do Paraná, Curitiba, 2014.

GÓMEZ-ZAMORANO, L. Y.; GARCÍAGUILLÉN, G.; ACEVEDO-DÁVILA, J. L. Estudo da Hidratação de Pastas de Cimento Portland com Substituições de Escória Granulada de Alto Forno, Cinza Volante e Metacaulim: efeito da utilização de dois aditivos superplastificantes. Revista Alconpat, v. 5, n. 2, p. 203-218, 2015.

GUTIÉRREZ, R. M. et al. Metakaolin Concrete: carbonation and chloride behavior. Revista Faculdad de Ingeniería Universidad de Antioquia, n. 48, p. 55-64, 2009.

HEEDE, P. V.; BELIE, N. A Service Life Based Global Warming Potential For High-Volume Fly Ash Concrete Exposed to Carbonations.

Construction and Building Materials, v. 55, p. 183-193, 2014.

HODHOD, O. A.; SALAMA, G. Simulating USB4908 by ANN Modeling to Analyse the Effect of Mineral Admixture With Ordinary and Pozzolanic Cements on the Sulfate Resistance of Concrete. Housing and Building National Research Center, v. 9, p. 109-117, 2013.

HOPPE FILHO, J. et al. Reactivity Assessment of Residual Rice-Husk Ashes. Journal of Materials in Civil Engineering, p. 04017003, 2017.

HOPPE FILHO, J. et al. Ataque de Matrizes Cimentícias por Sulfato de Sódio: adições minerais como agentes mitigadores. Cerâmica, v. 61, p. 168-177, 2015.

HOPPE FILHO, J. et al. High-Volume Fly Ash Concrete with and without Hydrated Lime: chloride diffusion coefficient from accelerated test. Journal of Materials in Civil Engineering, v. 25, p. 411-418, 2013.

LEE, G. et al. Effects of Crushed Glass Cullet Sizes, Casting Methods and Pozzolanic Materials on ASR of Concrete Blocks. Construction and Building Materials, v. 25, n. 5, p. 2611-2618, 2011.

MARQUES, P. F.; CHASTRE, C.; NUNES, A. Carbonation Service Life Modelling of RC Structures for Concrete with Portland and Blended Cements. Cement and Concrete Composites, v. 37, n. 3, p. 171-184, 2013. 
MEDEIROS, M. H. F. et al. High Strength Reinforced Concrete With Metakaolin and Silica Fume in Marine Environment: an experimental work. Hormigón y Acero, v. 63, p. 57-66, 2012.

MEDEIROS JUNIOR, R. A. et al. Investigação da Resistência à Compressão e da Resistividade Elétrica de Concretos Com Diferentes Tipos de Cimento. Revista ALCONPAT, v. 4, p. 116-132, 2014.

MEDEIROS, M. H. F. et al. Pozolanas de Elevada Reatividade: uma avaliação crítica do ensaio de Índice de Atividade Pozolânica (IAP) com cal usando Difração de Raios X. Ambiente Construído, Porto Alegre, v. 15, n. 3, p. 19-29, jul./set. 2015.

MEDINA, E. A. Pozolanicidade do Metacaulim em Sistemas Binário Com Cimento Portland e Hidróxido de Cálcio. São Paulo, 2011. Dissertação (Mestrado em Engenharia Civil) Escola Politécnica, Universidade de São Paulo, São Paulo, 2011

MEHTA, P. K.; MONTEIRO, P. J. M. Concreto: estrutura, propriedades e materiais. IBRACON. São Paulo, 2008

NITA, C. Utilização de Pozolanas em Compósitos de Cimento Reforçados Com Fibras de Celulose e PVA. São Paulo, 2006. Dissertação (Mestrado em Engenharia Civil e Urbana) - Escola Politécnica, Universidade de São Paulo, São Paulo, 2006.

NITA, C.; JOHN, V. M. Materiais Pozolânicos: o metacaulim e a sílica ativa. Boletim Técnico da Escola Politécnica da USP, BT/PCC/451, p. 1-13, 2007.

PACHECO-TORGAL, F.; JALALI, S. Sulphuric Acid Resistance of Plain, Polymer Modified, and Fly Ash Cement Concretes. Construction and Building Materials, v. 23, p. 3485-3491, 2009.

PAPADAKIS, V. G. Effect of Supplementary Cementing Material on Concrete Resistance Against Carbonatation and Chloride Ingress. Cement and Concrete Research, v. 30, n. 2, p. 291-299, 2000

PESSÔA, P. O. A.; NEPOMUCENO, A. A. Influência do Consume de Cimento na Corrosão de Armaduras em Argamassas de Cimento Sujeitas à Carbonatação. In: CONFERÊNCIA SOBRE TECNOLOGIA DE EQUIPAMENTOS, 6 ; CONGRESSO BRASILEIRO DE CORROSÃO, 22., Salvador, 2002. Anais... Salvador, 2002.
PICANÇO, M. de S.; ANGÉLICA, R S.; BARATA, M. S. Cimentos Portland Aditivados Com Arenito Zeolítico Com Propriedades Pozolânicas. Revista Matéria, v. 19, n. 2, p. 6880, 2014.

POON, C. S.; KOU, S. C.; LAM, L. Compressive Strength, Chloride Diffusivity and Pore Structure of High Performance Metakaolin and Silica Fume Concrete. Construction and Building Materials, v. 20, n. 10, p. 858-865, 2006.

POSSAN, E. Modelagem da Carbonatação e Previsão de Vida Útil de Estruturas de Concreto em Ambiente Urbano. Porto Alegre, 2010. Tese (Doutorado em Engenharia Civil) Escola de Engenharia, Universidade Federal do Rio Grande do Sul, Porto Alegre, 2010.

QUARCIONI, V. A. et al. Indirect and Direct Chapelle's Methods for the Determination of Lime Consumption in Pozzolanic Materials. Revista IBRACON de Estruturas e Materiais, v. 8, p. 17, 2015.

RAISDORFER, J. W. Influência da Adição ou Substituição de Adições Minerais ao Cimento Portland: efeitos na carbonatação, absorção capilar e resistividade de concretos. Curitiba, 2015. Dissertação (Mestrado em Engenharia de Construção Civil) - Escola de Engenharia, Universidade Federal do Paraná, Curitiba, 2015.

RILEM. CPC-18 Measurement of Hardened Concrete Carbonation Depth. Materials and Structures, v. 21, n. 126, p. 453-455, 1988.

RILEM. TC 116-PCD Permeability of Concrete as a Criterion of Its Durability Final Report: concrete durability - an approach towards performance testing. Materials and Structures, v. 21, n. 126, p. 453-455, 1988.

SILVA, K. D. do C. Avaliação da Atividade Pozolânica dos Resíduos de Lã de Rocha, Fibra de Vidro e lã de Vidro. Ouro Preto, 2016. Dissertação (Mestrado em Engenharia Civil) Escola de Minas, Universidade Federal de Ouro Preto, Ouro Preto, 2016.

TORRES-AGREDO, J.; MEJÍA-DEGUTIÉRREZ, R.; DELVASTO-ARJONA, S. Effects of Metakaolin Percentages in the Final Properties of Blended Concrete. Revista Ingeniería e Investigación Universidad Nacional de Colombia, v.15, n. 1, p. 77-90, 2011.

TUUTTI, K. Corrosion of Steel in Concrete. Stockholm: Swedish Cement and Concrete Research Institute, 1982. CBI Forskning research. 
VAITKEVICIUS, V.; SERELIS, E.; HILBIG, H. The Effect of Glass Powder on the Microstructure of Ultra High Performance Concrete.

Construction and Building Materials, v. 68, p. 102-109, 2014.

VOGLIS, N.; KAKALI, G.; TSIVILIS, S.

Identification of Composite Cement Hydration

Products by Means of X-Ray Diffraction.

Mikrochimica Acta, v. 126, p. 181-183. 2001

ZERBINO, R. et al. Alkali-Silica Reaction in

Mortars and Concretes Incorporating Natural Rice

Husk Ash. Construction and Building Materials,

v. 36, p. 796-806, 2012.

\section{Agradecimentos}

Os autores deste trabalho agradecem ao Conselho Nacional de Desenvolvimento Científico e Tecnológico (CNPq) e à Fundação Araucária pelo financiamento dos equipamentos que deram suporte a esta pesquisa. Além disso, agradecemos ao Departamento Nacional de Infraestrutura de Transportes (DNIT) pela concessão de bolsas de estudo para a equipe da pesquisa, e à Universidade Federal do Oeste da Bahia pela realização de ensaios de difratometria de raios $\mathrm{X}$.

Marcelo Henrique Farias de Medeiros

Departamento de Construção Civil, Centro Politécnico | Universidade Federal do Paraná | Av. Coronel Francisco Heráclito dos Santos, 210, Jardim das Américas | Curitiba - PR - Brasil | CEP 81531-980 | Tel.: (41) 3361-3438 | E-mail: medeiros.ufpr@gmail.com

\section{Janderson William Raisdorfer}

Departamento de Construção Civil, Centro Politécnico | Universidade Federal do Paraná | E-mail: janderwr@gmail.com

\section{Juarez Hoppe Filho}

Centro das Ciências Exatas e das Tecnologias | Universidade Federal do Oeste da Bahia | Rua Professor José Seabra de Lemos, 316, Recanto dos Pássaros | Barreiras - BA - Brasil | CEP 47808-021 | Tel.: (77) 3614-3145 | E-mail: juarez.hoppe@gmail.com

\section{Revista Ambiente Construído}

Associação Nacional de Tecnologia do Ambiente Construído

Av. Osvaldo Aranha, $99-3^{\circ}$ andar, Centro

Porto Alegre - RS - Brasil

CEP 90035-190

Telefone: +55 (51) 3308-4084

Fax: +55 (51) 3308-4054

www.seer.ufrgs.br/ambienteconstruido

E-mail: ambienteconstruido@ufrgs.br 